\title{
Role of an Arabidopsis Rab GTPase RabG3b in Pathogen Response and Leaf Senescence
}

Soon Il Kwon • Hong Joo Cho • Kisuk Bae •

Jin Hee Jung • Hak Chul Jin • Ohkmae K. Park

Published online: 16 May 2009

(C) The Botanical Society of Korea 2009

Erratum to: J. Plant Biol. (2009) 52:79-87

DOI 10.1007/s12374-009-9011-4

The article was published as a Review. It is actually Original Research.

The online version of the original article can be found at http://dx.doi. org/10.1007/s12374-009-9011-4.

S. I. Kwon $\cdot$ H. J. Cho $\cdot$ K. Bae $\cdot$ J. H. Jung $\cdot$ H. C. Jin •

O. K. Park $(\square)$

School of Life Sciences and Biotechnology, Korea University,

Anam-dong, Seongbuk-gu,

Seoul 136-701, Korea

e-mail: omkim@korea.ac.kr 